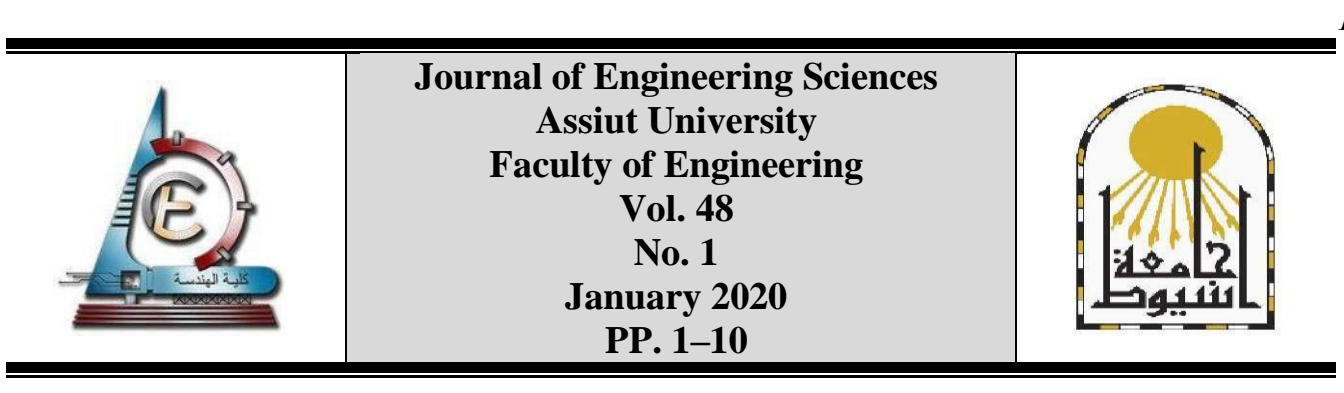

\title{
SMART CRITICAL PATH METHOD AS A MODIFIED DETAILED SCHEDULING TECHNIQUE
}

\author{
Yasser M. R. Aboelmagd \\ Civil Eng. Depart College of Engineering, University of Business \& Technology(UBT), Jeddah, Saudi Arabia. \\ Mathematics and Physics Eng. Depart, Faculty of Engineering, Alexandria University, Egypt.
}

Received 28 July 2019; Accepted 7 August 2019

\begin{abstract}
Now more Construction managers depends on scheduling tools based Critical Path Method (CPM) to can obtain total project duration plus activities' float that leads to more efficiency for controlling and planning the studied construction projects. CPM was the best tool for construction projects time schedule but nowadays researchers were focused on drawbacks that loose its use as a decision making technique. This paper shows most of CPM drawbacks and discusses a modified tool for CPM model that is named Critical Path Segments (CPS). This CPS scheduling technique solves CPM drawbacks by three main ways: (1) Dividing duration of project activity into separated time segments; (2) All activities relationships were switched into sequential relation as finish to start and (3) Calculations and analysis were done by using forward path. Sample cases of studies were included to focus on CPM shortages and CPS detailed calculations and analysis were illustrated showing this CPS technique can handle the schedules by best way.
\end{abstract}

Keywords: Scheduling; Critical Path method; Critical Path Segments; time control and Construction management.

\section{Introduction}

The CPM technique was presented and tested as a scheduling technique from 1956 to 1958 , since this time and till present it is the most widely used scheduling technique, it finds the minimum project duration according to possible activities start and finish times with its floats, it defines the critical path, and estimate the impact of changes in durations, logic sequence, and project finish time. Despite all the previous advantages of CPM use, the CPM technique and its software applications still limited tools with many points of weakness in scheduling and monitoring processes [1].

\section{Trials of enhancing critical path method}

In recent years, researchers tried to present alternative scheduling techniques and others present a modified model of CPM such as follows:

It was introduced the way of improving CPM is to change all start to start and finish to finish relationships into sequential finish to start. This way converts complex relationships 
into more added activities that its duration's is equal to old relationship lag. It results a more complicated network [2].

It was proposed a new system is named Relationship Diagramming Method (RDM), which it saves additional codes and information for any relationship, which are more than 4 as common in CPM, such as progressed to start [3].

It was presented a scheduling technique resembles the Arrow Diagramming Method, but on a time scale. It uses activity notation, all non-traditional relationships types (SS-FFSF) are allowed by adding nodes between activities or between the activities start and finish nodes. He called the Logic diagramming Method (LDM) [4].

It was proposed a generic transform schemes to convert all start to start and finish to finish relationships and detected them automatically into equivalent sequential finish to start on PDM networks [5].

It was introduced new Critical Path Segments (CPS) as a new scheduling tool of representing the activity duration not as a solid bar but as separated, its number equal to the number of time units of the activity duration. This way allows all non-finish-to-start relationships to be presented as a finish to start with the segment that meet the relationship type. This technique is the topic of this research [6].

CPM was a genius scheduling technique till the $21^{\text {st }}$ century, when construction field's challenges are different than the previous one, on this time many shortages are noticed in CPM. Because of CPM advancements, benefits and its variation, Precedence Diagram Method (PDM) in construction site had increased in last three decades [7]. CPM computing efficiency and analytical capabilities need to be enhanced for construction projects to can meet the changing requirements [8].

\section{Areas of shortage in critical path method}

A classification for the CPM shortages was identified to make more focus on the areas needed to be enhanced, there are 3 areas;

(1) Relationships representation and logic sequence; the logic relationships among activities as start to start and finish to finish express time dependencies not work amount dependencies [9].

(2) Scheduling analysis and outputs [10];

a. Using the finish to finish and/or start to start relationships cause analysis complexity for the project network, as these multiple relationships make a small segment of activity is critical not all activity which is not available to be shown in CPM software.

b. The use of leads and lags in relationships can cause inaccurate calculations of floats, and critical path.

(3) Project controlling and monitoring; the remaining duration analysis for an activity isn't real and accurate all the time [11].

\subsection{Relationships representation and logic sequence}

CPM uses relationships to indicate time dependencies, when the project is in execution stage activity actual duration may differs than planned because of many reasons are explained later in details. This changing in duration of preceding activity may affect succeeding one as shown in figure 1. 


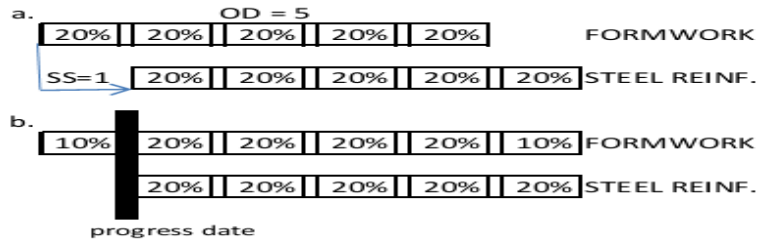

Fig. 1. CPM Relationship based on time dependency.

In figure 1, two activities; formwork and steel reinforcement are illustrated with a $\mathrm{SS}=1$ to express the overlap between the 2 jobs, which means also that each $20 \%$ of formwork is followed by $20 \%$ of steel reinforcement. A formwork delay of 1 day is assumed, the time dependency relation SS=1 ignore the $20 \%$ that must be finished before the start of the steel reinforcement, while the production dependency relation respect the progress percent.

\subsection{Scheduling analysis and outputs}

As mentioned, non-traditional relationships as start to start, finish to finish, and start to finish complicate the project network and may cause partially critical activities in which the start date of the activity is critical while the finish date is not, as illustrated in figure 2. CPM analysis and software systems cannot recognize the partially critical activity as it takes the activity as one unit critical or non-critical [12].

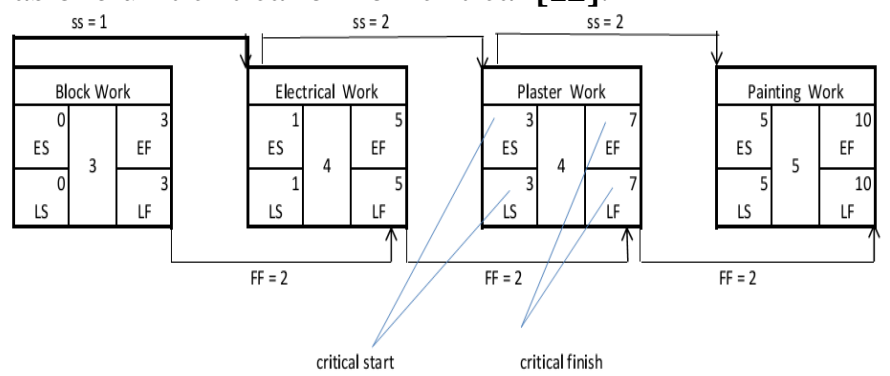

Fig. 2. CPM Calculations for critical activities.

The figure shows a sample of a 4 activities network is linked by both start to start and finish to finish relationship. The CPM calculations are as shown in the figure, because of considering the activity as a one unit, "plaster work" activity is considered as a critical activity as a whole, while it's a partially critical activity as shown in the following figure 3 ., the activity finish is critical-doesn't have any float- while the start is not critical and contains 1 day float [12].

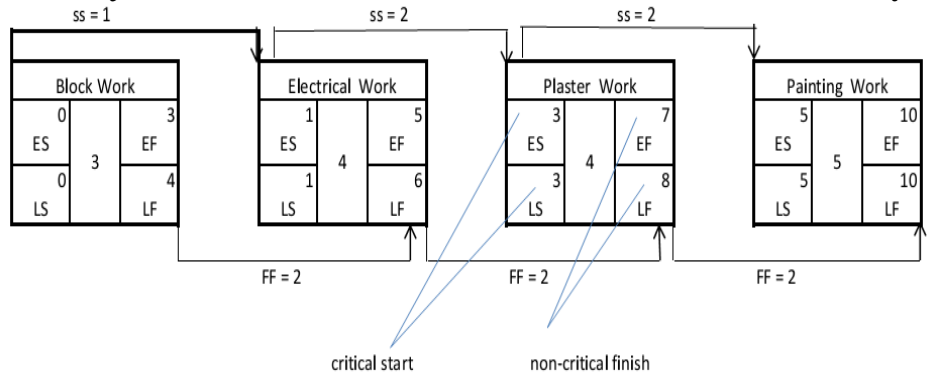

Fig. 3. Partially critical activities.

Such a situation doesn't provide a clear picture to the planner about the project critical path which is essential for taking right decisions about project crashing, and project updates. 


\subsection{Project controlling and monitoring}

Activities durations are one of the schedule bases, the planner estimates these durations based on the production rates and the budget quantities of activities. When the schedule is updated with the actual progress and there is an activity delays, in CPM there are two assumptions; the first one (case a) is that the delay is exceptional and the production rate of the activity will continue as planned. The second opinion (case b) is that the planned production rate is faster than the actual one, so the original duration of the activity needed to be edited. Either the first or the second opinion reflects on the calculations of the activity remaining duration as shown in figure 4 .
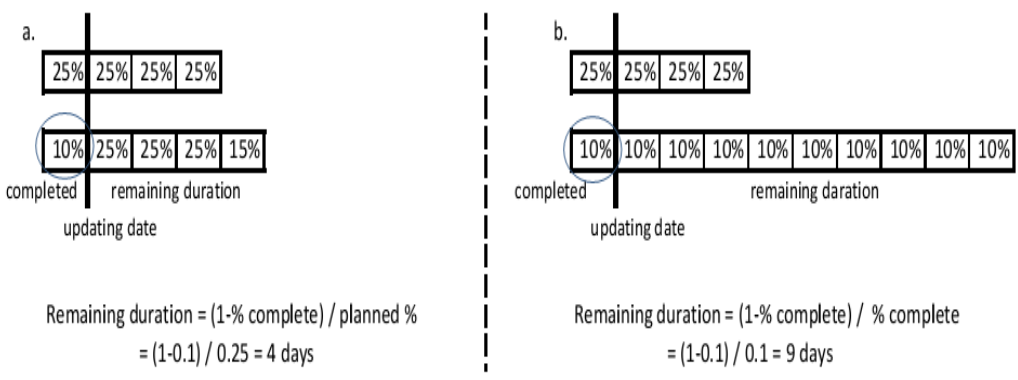

Fig. 4. Calculations of remaining duration.

A four days duration activity is shown, at progress date the actual progress is delayed than the planned one, and the two opinions calculations are explained in figure 4. CPM doesn't consider a situation like a delay caused by the owner for urgent meeting, or by the consultant for material changing order ... etc. The activity delay may be for any other reason not only because of the production rate. For the previous illustrated reasons, a new representation and a modified model of CPM is needed which addresses all mentioned shortages.

\section{Critical path segments scheduling tool}

The Critical path segments scheduling tool is a modified model of the Critical path method, from the previously mentioned areas of shortage in CPM; the 2 main factors are the activities representation and the type of relationships which are modified in the CPS to suit with the construction scheduling needs. CPS shows each activity in the network as a separated time segments that its number equal to activity duration. That means a four days activity duration is represented by 4 time segments, this representation allows all type of relationships as ( $\mathrm{SS}-\mathrm{FF}-\mathrm{SF}$ ) to be converted to a FS relationship with zero lag, examples are illustrated in successor sections in this paper.

\section{CPM problems and CPS solutions}

CPM areas of shortage are previously mentioned, sample cases are recalculated with CPS to show how the modified technique can be useful in these cases.

\subsection{Relationships representation and logic sequence}

The illustrated example in figure 1 shows a defect in the time based relationships when the project progress is updated it may cause a different dependency than the planned one. A new type of relationship is suggested in the CPS based on the amount of work or the production of the activity not the time; in figure 5 the same example in figure 1 is recalculated with the CPS. 


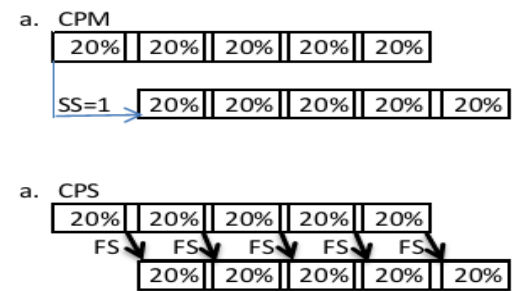

Fig. 5. CPS Relationship based on production dependency.

The production based relationships all are FS with zero lags but it links the activity percent of work and in project update the progress percent of the activity leads the relation not the time.

\subsection{Scheduling analysis and outputs}

The illustrated example in figure 2 the problem of a partially critical activity may exist in the project schedule and how the CPM isn't able to recognize such an activity and it consider that activity as a totally critical one. The CPS solves this problem by its activity representation as the activity is divided into segments, so it is normal to find in the same activity both critical and non-critical segments as shown in figure 6 .

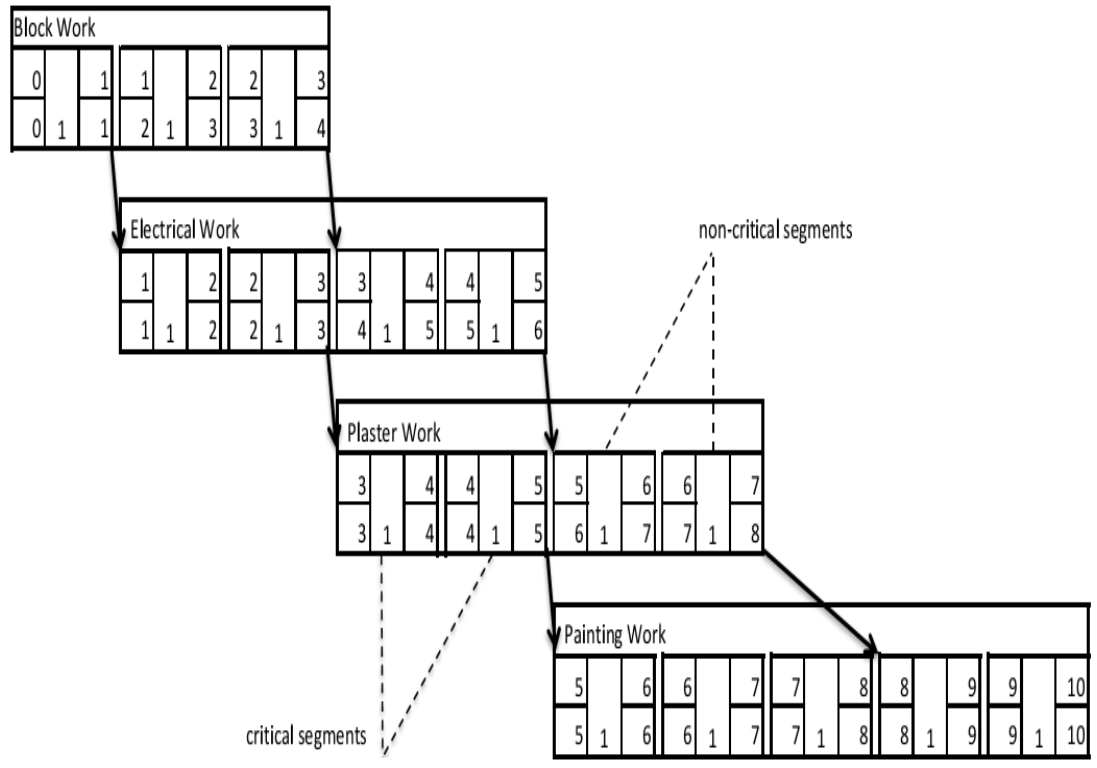

Fig. 6. CPS Calculations for critical activities.

\subsection{Project controlling and monitoring}

CPM ignores the delays caused by any other reason than the production rate. In both ways of remaining duration analysis - planned progress or actual progress - it considers that the activity duration and remaining duration depend on the production rates only, although there are delays by the owner or the contractor or even the weather conditions as shown in figure 7 . 


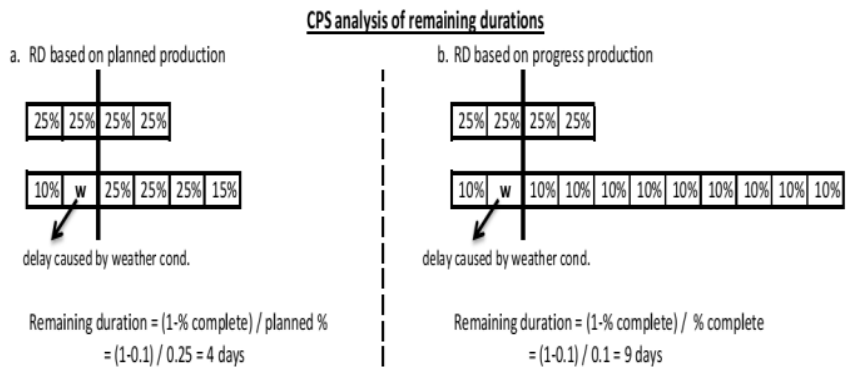

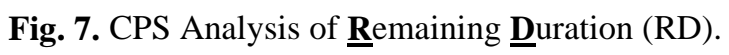

\section{Critical path segments conversion analysis}

This section introduces how to convert all schedule data from the CPM into the CPS; activities representation, and relationships among activities.

\subsection{Converting activities durations representation}

The activity duration estimation is the first step in project planning, CPM deals with this duration as a one solid bar while the CPS deals with as separated but connected segments. The number of segments in any activity equals to the number of time periods of its duration. i.e.: an activity of 4 days duration has four time segments as shown in figure 8.

\section{Representation of a 4 days activity duration}

\section{$\underline{\text { CPM }}$}

CPS

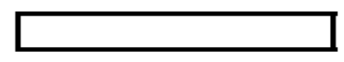

Fig. 8. Activity duration representation in CPM and CPS.

\subsection{Converting activities relationships based on time dependency}

(1)For finish to start relationship: (See Figure 9)

- Case (a) of FS with lag = zero, create a FS relation between the last time segment of the predecessor activity and the first time segment of the successor activity.

- Case (b) of FS with lag = number $(\mathrm{N})$, create start-delay time segments (dummy segments) in the start of the successor activity. The number of the start-delay segments $=(\mathrm{N})$, equals the lag time, then link the last time segment of the predecessor activity with the first start-delay time segment of the successor activity.

Finish - to - finish relationship in CPM \& CPS:

1. FS with lag $=$ Zero
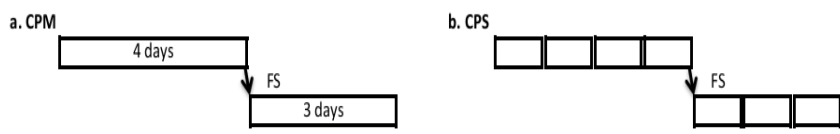

2-F5 with lag $=2$ days

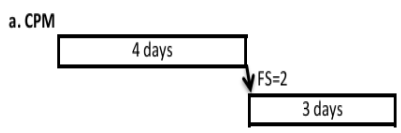

b. CPS

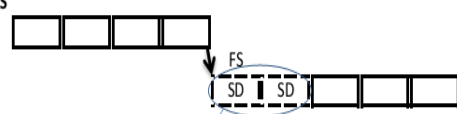

Fig. 9. Converting the finish to start relationship with and without time lag. 
(2)For start to start relationship: (See Figure 10)

- Case (a) of SS with lag = zero, create a FS relation between the first time segments of both predecessor and successor activities.

- Case $(b)$ of SS with lag = number $(\mathrm{N})$, create a FS relation between the time segment number $(\mathrm{N})$ of the start of the predecessor activity, where $(\mathrm{N})=$ time lag, and the first time lag of the successor activity.

\section{Start - to - start relationship in CPM \& CPS:}

a. CPM

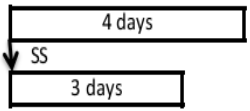

a. CPM

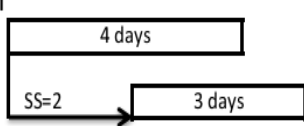

1. SS with lag = Zero

b. CPS

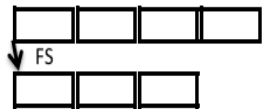

2. 55 with lag $=2$ davs

b. CPS

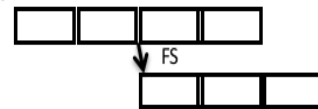

Fig. 10. Converting the start to start relationship with and without time lag.

(3) For finish to finish relationship: (See Figure 11)

- Case (a) of FF with lag = zero, create a FS relation between the last time segments of both predecessor and successor activities.

- Case (b) of FF with lag = number $(\mathrm{N})$, create a FS relation between the last time segment of the predecessor activity and the time segment number (N) counted from the end of the successor activity.

Finish - to - finish relationship in CPM \& CPS:

1. FF withlag = Zero

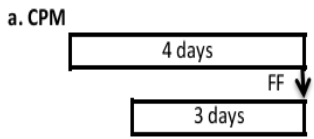

b. CPS

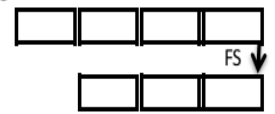

2. FF with lag $=2$ days

a. CPM

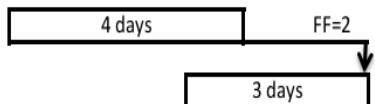

b. CPS

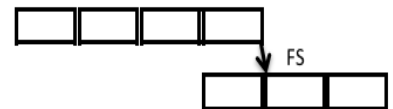

Fig. 11. Converting finish - to - finish relationship with and without time lag.

(4)For start to finish relationship: (See Figure 12)

- Case (a) of SF with lag = zero, create a FS relation between the first time segment of the predecessor activity and the last time segment of the successor activity.

- Case (b) of SF with lag = number $(\mathrm{N})$, create a FS relation between the first time segment of the predecessor activity and the time segment number $(\mathrm{N})$ counted from the end of the successor activity. 


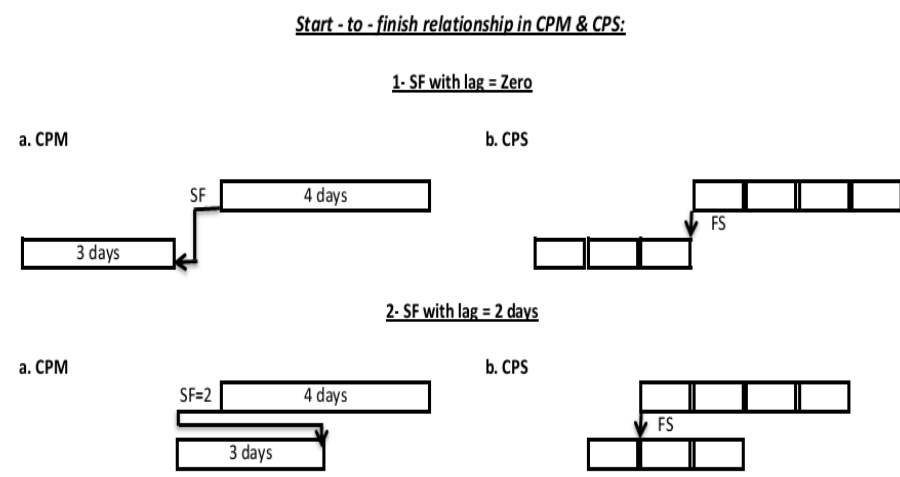

Fig. 12. Converting start to finish relationship with and without time lag.

\section{Critical path segments calculations}

The CPS presents a new schedule calculations based on forward path only without a backward one, which means that it needs a new approach to determine the floats as follows:

\subsection{Dates, floats, and critical path analysis}

The following examples show the calculations of activities dates, floats, and the critical path determination with the CPS scheduling with forward path only. In figure 13, the presented example shows the CPS calculations;

(1) All network paths are identified (two paths in example 1 and seven paths in example2).

(2) Each activity is marked by the path it lays on (i.e. Activity A lies on paths 1,2 in example 1)

(3) As all the relationships are FS $=0$, the paths durations can be calculated as the sum of its activities durations (i.e. $22-20$ days in example 1).

(4) The critical path is simply identified as the longest path duration, which is also the project duration (22 days in example 1 and 16 days in example 2).

(5) Identifying the paths floats as the difference between the path duration and the longest path duration (i.e. $22-20=2$ days in example 1 ).

(6) After paths floats identification, each activity has a total float equals to the minimum of all the path floats which it lays on (i.e. Activity A lays on path 1,2 and $\mathrm{TF}_{\mathrm{A}}$ is equal to the minimum path float which is for path $1=$ zero in example 1 ).

Table 1.

Details of illustrative examples.

\begin{tabular}{|c|c|c|c|c|c|c|}
\hline \multicolumn{3}{|c|}{ illustrative example (1) } & \multicolumn{4}{|c|}{ illustrative example (2) } \\
\hline \begin{tabular}{|l} 
Activity \\
\end{tabular} & Duration Days & Depends on & Activity & Duration Days & Depends on & Lag \\
\hline A & 5 & - & A & 5 & - & - \\
\hline $\mathrm{B}$ & 2 & $A$ & $B$ & 7 & $\mathrm{~A}$ & $\mathrm{SS}=6$ \\
\hline C & 6 & B & C & 2 & $\begin{array}{l}\mathrm{A} \\
\mathrm{H}\end{array}$ & $\begin{array}{l}\mathrm{FF}=3 \\
\mathrm{FS}=1\end{array}$ \\
\hline E & 10 & $\mathrm{~A}$ & E & 4 & $\mathrm{C}$ & $\mathrm{FS}=4$ \\
\hline F & 7 & $\mathrm{C}$ & $\mathrm{F}$ & 6 & $\begin{array}{l}\mathrm{A} \\
\mathrm{C}\end{array}$ & $\begin{array}{l}\mathrm{SF}=9 \\
\mathrm{FF}=7\end{array}$ \\
\hline $\mathrm{G}$ & 3 & E & $\mathrm{G}$ & 8 & $\mathrm{H}$ & $\mathrm{SS}=6$ \\
\hline $\mathrm{H}$ & 2 & $\mathrm{~F}, \mathrm{G}$ & $\mathrm{H}$ & 3 & - & - \\
\hline
\end{tabular}




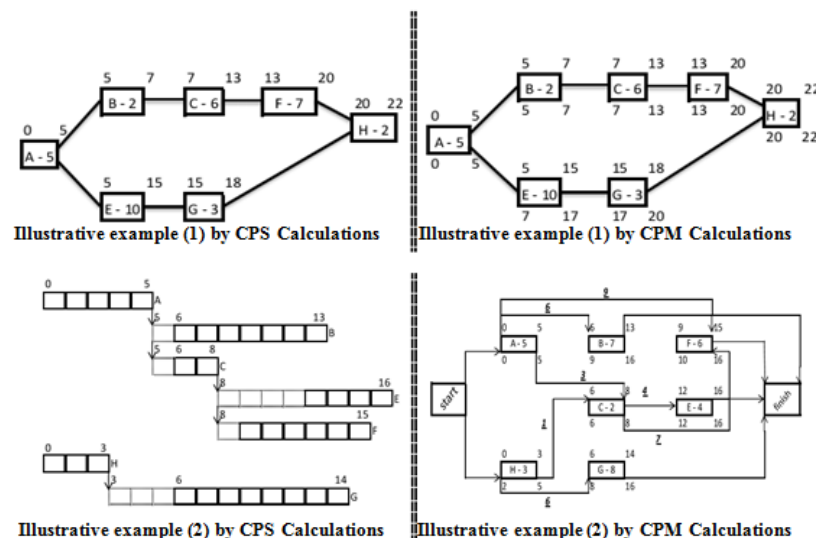

Fig. .13. Comparison between CPM and CPS calculations of dates and floats.

Table 2.

Analysis of illustrative examples.

\begin{tabular}{|c|c|c|c|c|c|c|c|c|c|c|c|}
\hline \multicolumn{6}{|c|}{ illustrative example (1) } & \multicolumn{6}{|c|}{ illustrative example (2) } \\
\hline Path & $\begin{array}{l}\text { Activiti } \\
\text { on Pat }\end{array}$ & \begin{tabular}{c|c} 
ies & $\begin{array}{c}P_{2} \\
\text { th }\end{array}$ \\
Dur
\end{tabular} & & $\begin{array}{l}\text { Long. } \\
\text { Path }\end{array}$ & $\begin{array}{l}\text { Path } \\
\text { Float }\end{array}$ & Path & $\begin{array}{l}\text { Activit } \\
\text { on } \mathrm{Pa}\end{array}$ & \begin{tabular}{c|c} 
ities & $\mathrm{Pa}$ \\
ath & Dur \\
\end{tabular} & th & $\begin{array}{l}\text { Long. } \\
\text { Path }\end{array}$ & $\begin{array}{l}\text { Path } \\
\text { Float }\end{array}$ \\
\hline 1 & $\mathrm{ABCF}$ & & & \multirow{2}{*}{22} & 0 & 1 & $\mathrm{AB}$ & \begin{tabular}{l|l}
3 & 1 \\
3
\end{tabular} & 3 & \multirow{7}{*}{16} & 3 \\
\hline 2 & $\mathrm{AEGF}$ & & & & 2 & 2 & $\mathrm{AF}$ & 0 & 9 & & 7 \\
\hline & & & & & & 3 & $\mathrm{ACF}$ & $\mathrm{E}$ & 6 & & 0 \\
\hline & & & & & & 4 & $\mathrm{ACF}$ & $\mathrm{F}$ & 5 & & 1 \\
\hline & & & & & & 5 & $\mathrm{HG}$ & & 4 & & 2 \\
\hline & & & & & & 6 & $\mathrm{HCF}$ & & 4 & & 2 \\
\hline & & & & & & 7 & $\mathrm{HCl}$ & $\mathrm{F}$ & 3 & & 3 \\
\hline \multirow[b]{2}{*}{ Activity } & \multirow[b]{2}{*}{ Path } & \multicolumn{2}{|c|}{ CPS } & \multicolumn{2}{|c|}{ CPM } & \multirow[b]{2}{*}{ Activity } & \multirow[b]{2}{*}{ path } & \multicolumn{2}{|c|}{ CPS } & \multicolumn{2}{|c|}{ CPM } \\
\hline & & $\begin{array}{l}\text { Path } \\
\text { Float }\end{array}$ & $\begin{array}{l}\text { Act. } \\
\text { Float }\end{array}$ & \begin{tabular}{l|l|} 
& $L F$ \\
\end{tabular} & $\begin{array}{c}\text { Act. } \\
\text { Float }\end{array}$ & & & $\begin{array}{l}\text { Path } \\
\text { Float }\end{array}$ & $\begin{array}{l}\text { Act. } \\
\text { Float }\end{array}$ & \begin{tabular}{l|l|} 
LF - ES \\
\end{tabular} & $\begin{array}{l}\text { Act. } \\
\text { Float }\end{array}$ \\
\hline A & 1,2 & 0,2 & 0 & $5-5$ & 0 & A & $1,2,3,4$ & $3,7,0,1$ & 0 & $5-5$ & 0 \\
\hline B & 1 & 0 & 0 & $7-7$ & 0 & B & & 3 & 3 & $16-13$ & 3 \\
\hline $\mathrm{C}$ & 1 & 0 & 0 & $13-13$ & 0 & $\mathrm{C}$ & $3,4,6,7$ & $0,1,2,3$ & 0 & $8-8$ & 0 \\
\hline $\mathrm{E}$ & 2 & 2 & 2 & $17-15$ & 2 & $\mathrm{E}$ & 3,6 & 0,2 & 0 & $16-16$ & 0 \\
\hline $\mathrm{F}$ & 1 & 0 & 0 & $20-20$ & 0 & F & $2,4,7$ & $7,1,3$ & 1 & $16-15$ & 1 \\
\hline $\mathrm{G}$ & 2 & 2 & 2 & $20-18$ & 2 & $\mathrm{G}$ & 5 & 2 & 2 & $16-14$ & 2 \\
\hline $\mathrm{H}$ & 1,2 & 0,2 & 0 & $22-22$ & 0 & $\mathrm{H}$ & $5,6,7$ & $2,2,3$ & 2 & $5-3$ & 2 \\
\hline
\end{tabular}

\section{Conclusion}

Critical Path Method (CPM) still used widely for scheduling construction projects, while its float calculation may make more errors especially in complex schedules during project control [13]. This paper had potential scheduling computations for resolving CPM problems and provides decision support capabilities to help improve project planning and control. This paper presented a modified model of CPM scheduling technique to enhance the Critical Path Segments (CPS) scheduling mechanism and incorporated all events detailed visualization. Also it used to calculate the modified float by forward pass to resolve float problems. Illustrative examples are solved to put detailed explanation for proposed mechanism and its project control benefits. CPS is expected to be more assistance to project planners in scheduling way to reflect deeply the reality and give more corrective actions with decisions. CPS which is addressed some of mentioned CPM shortages and there are other shortages which haven't been covered in this paper such as: (1) Time constraints which ignore the logic sequence of project network; (2) Out of sequence progress makes CPM analysis more 
difficult and complex; and (3) Other shortages areas will be appeared in Resource management. CPS is a good tool which can be done extended studies by future researchers.

\section{REFERENCES}

[1] Jeonghoon L., Moonseo P., Hyun-Soo L. and Hosang H. (2019) "Classification of Modular Building Construction Projects Based on Schedule-Driven Approach" Journal of Construction Engineering and Management, Volume 145 Issue 5.

[2] Herold S. C. (2004) "Enhanced PDM - Concepts and benefits." AACE International Transactions, PS.09.1-PS.09.8.

[3] Plotnick F.L. (2006) "RDM - Relationship diagramming method" AACE International Transactions, PS.08.1-PS.08.10.

[4] Ponce de Leon, G. (2008) "Project planning using logic diagramming method" AACE International Transactions, PS.S05.1-PS.S05.6.

[5] Lu M., and Lam H. (2009) "Transform schemes applied on non-finish-to-start logical relationships in project network diagrams" Journal of Construction Engineering and Management, ASCE, 135 (9), 863-873.

[6] Menesi W. (2010) "Construction Scheduling Using Critical Path Analysis with Separate Time Segments" A thesis presented to the University of Waterloo for the degree of Doctor of Philosophy in Civil Engineering Waterloo, Ontario, Canada, 2010.

[7] Kerzner H. (2001) "A system approach to planning, scheduling and controlling" John Wiley \& Sons, Inc., 2001.

[8] Ahuja V. and Thiruvengadam V. (2004) "Project scheduling and monitoring: current research status." Construction Innovation, 4 (1), 19-31.

[9] Hammad M., Abbasi A. and Ryan M. (2018) "Developing a Novel Framework to Manage Schedule Contingency Using Theory of Constraints and Earned Schedule Method" Journal of Construction Engineering and Management, Volume 144 Issue 4.

[10] Pablo B. (2017) "M-PERT: Manual Project-Duration Estimation Technique for Teaching Scheduling Basics" Journal of Construction Engineering and Management, Volume 143 Issue 9.

[11] Ma G., Wang A., Li N. and Gu L. (2014) "Improved Critical Chain Project Management Framework for Scheduling Construction Projects" Journal of Construction Engineering and Management, Volume 140 Issue 12.

[12] Said H. and Lucko G. (2016) "Float Types in Construction Spatial Scheduling" Journal of Construction Engineering and Management, Volume 142 Issue 12.

[13]Fan S. (2012) "Modified Time Impact Analysis Method" Journal of Construction Engineering and Management, Volume 138 Issue 2.

\section{طريقة المسار الحرج الأكية كإسلوب مطور و مفصل للجدولة الزمنية فى مشروعات التثييا}

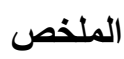

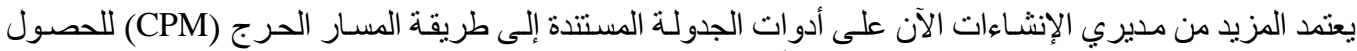

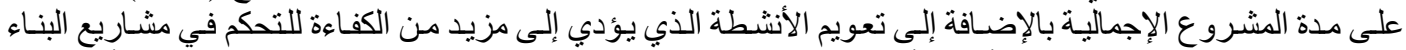

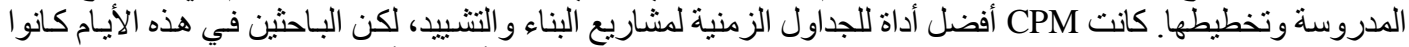

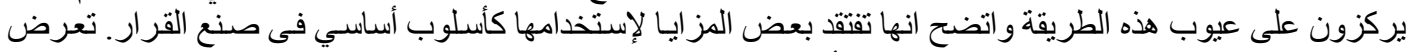

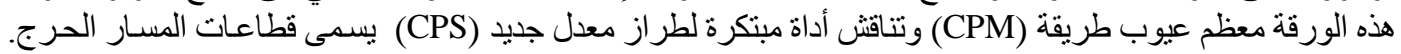

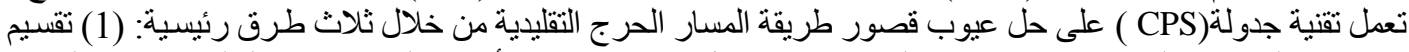

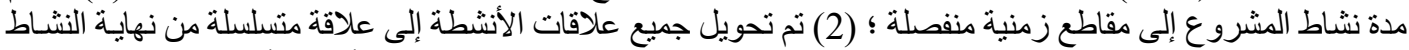

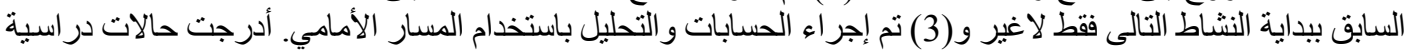

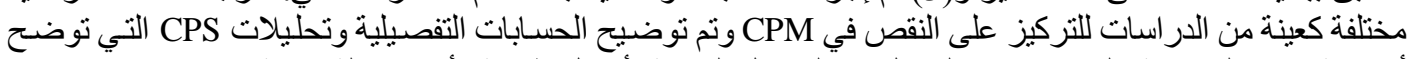
أن تقنية CPS المقترحة بالبحث يمكنها التعامل مع الجداول الزمنية بأفضل طريقة الفئة أدق جدولة زمنية. 